\title{
Genetics of primary bilateral macronodular adrenal hyperplasia: a model for early diagnosis of Cushing's syndrome?
}

\author{
Ludivine Drougat ${ }^{1}$, Stéphanie Espiard' ${ }^{1}$ and Jerôme Bertherat ${ }^{1,2}$ \\ ${ }^{1}$ Institut National de la Santé et de la Recherche Médicale (INSERM) U1016, Centre National de la Recherche \\ Scientifique (CNRS) UMR 8104, Institut Cochin, Université Paris-Descartes, 75014 Paris, France and ${ }^{2}$ Department of \\ Endocrinology, Referral Center for Rare Adrenal Diseases, Assistance Publique Hôpitaux de Paris, Hôpital Cochin, 27 \\ rue du Faubourg St Jacques, 75014 Paris, France
}

Correspondence should be addressed to J Bertherat Email

jerome.bertherat@aphp.fr

\begin{abstract}
Long-term consequences of cortisol excess are frequent despite appropriate treatment after cure of Cushing's syndrome. This might be due to diagnostic delay, often difficult to reduce in rare diseases. The identification of a genetic predisposing factor might help to improve early diagnosis by familial screening. Primary bilateral macronodular adrenal hyperplasia (PBMAH) is a rare cause of Cushing's syndrome. Hypercortisolism in PBMAH is most often diagnosed between the fifth and sixth decades of life. The bilateral nature of the adrenocortical tumors and the occurrence of rare clear familial forms suggest a genetic origin. Indeed, a limited subset of PBMAH can be observed as part of multiple tumors syndromes due to alterations of the APC, Menin or Fumarate Hydratase genes. Rare variants of the phosphodiesterases PDE11A have been associated with PBMAH. The recent identification of ARMC5 germline alterations in 25-50\% of PBMAH patients without obvious familial history or associated tumors opens new perspectives. ARMC5 alterations follow the model of a tumor suppressor gene: a first germline inactivating mutation of this $16 \mathrm{p}$ located gene is followed by a somatic secondary hit on the other allele (inactivating mutation or allelic loss). Functional studies demonstrate that ARMC5 controls apoptosis and steroid synthesis. The phenotype of index cases patients with the mutation seems more severe than the one of WT index cases. However, phenotype variability within a family is often observed. This review summarizes the genetics of PBMAH, focusing on ARMC5, which offer new perspectives for early diagnosis of Cushing's syndrome.
\end{abstract}

\section{Introduction}

Primary bilateral macronodular adrenal hyperplasia (PBMAH) is an adrenal cause of Cushing's syndrome (CS) due to the bilateral development of adrenocortical nodules (1). Previously called massive macronodular adrenocortical disease, primary macronodular adrenal hyperplasia or bilateral macronodular hyperplasia, bilateral form are more likely genetic. CS due to primary adrenal hypersecretion is classified as ACTH-independent

Invited Author's profile

Jérôme Bertherat is Professor of Endocrinology at Paris Descartes University, Chief of the Endocrinology Department of Cochin Hospital, Head of the National Center for Rare Adrenal Diseases and of the research team 'Genomics and Signaling of Endocrine Tumors' in the Cochin Institute (INSERM U1016 \& CNRS UMR8104), Paris, France. He serves as the coordinator of the French National Network for Rare Endocrine Disorders (FIRENDO) and as chair of the Clinical Committee of the European Society of Endocrinology (ESE). He is currently member of the executive committees of the ESE, of the ENSAT network dedicated to adrenal tumors and of the French Endocrine Society. His main research specialties include Cushing's syndrome, the genetics of familial adrenal tumors and the molecular genetics of endocrine tumors.

(c) 2015 European Society of Endocrinology Printed in Great Britain Published by Bioscientifica Ltd.
This article is adapted from work presented at IMPROCUSH-1, 12-14 October 2014. The meeting was supported by the European Science Foundation, Deutsche Forschungsgemeinschaft, Carl Friedrich von Siemens Stiftung, European Neuroendocrine Association and the Deutsche Geselitschaft furt Endokrinologie. The oppinions of views expressed in this article are those of the authors, and do not necessarily reflecte access the opinions or recommendations of the supporters of the symposium. 
CS, and PBMAH was also named ACTH-independent macronodular adrenal hyperplasia (AIMAH). Louiset et al. (2013) reported that the cortisol secretion in PBMAH is not truly ACTH-independent (2), since the adrenocortical tumor cells express ACTH, and this locally produced ACTH stimulates in a paracrine and autocrine fashion the cortisol secretion (Fig. 1). Considering that ACTH could play a role in this disease, it was then suggested to name it PBMAH, to avoid the confusing reference to 'ACTH-independence' (3). The concept of illegitimate receptor expression was mostly demonstrated after the investigation of PBMAH patients, and this phenomenon is observed in the majority of PBMAH patients $(1,4,5,6)$.

PBMAH can be diagnosed in patients with clinical signs of cortisol excess, usually in the fifth or sixth decade of life
(1). PBMAH is also nowadays often diagnosed after the investigation of an adrenal incidentaloma. Adrenal incidentalomas can be observed in $0.4-5 \%$ of the general population, and are bilateral in $10-15 \%$ of the cases, corresponding mostly to PBMAH (7). CS can be diagnosed in about $35 \%$ of these bilateral incidentalomas $(7,8)$. CS in PBMAH is often mild and insidious, even if serious forms can be encountered. PBMAH seems to be predominant in females as observed with other causes of CS $(9,10,11)$. Finally, the exact prevalence of PBMAH in the general population is unknown and dependent of the diagnosis criteria.

CS is responsible for many manifestations, including cardiovascular disease, neuropsychiatric disorders, osteoporosis, glucose intolerance or diabetes. The many consequences of CS lead to significant impairment of quality of life. Several studies suggest that despite the cure

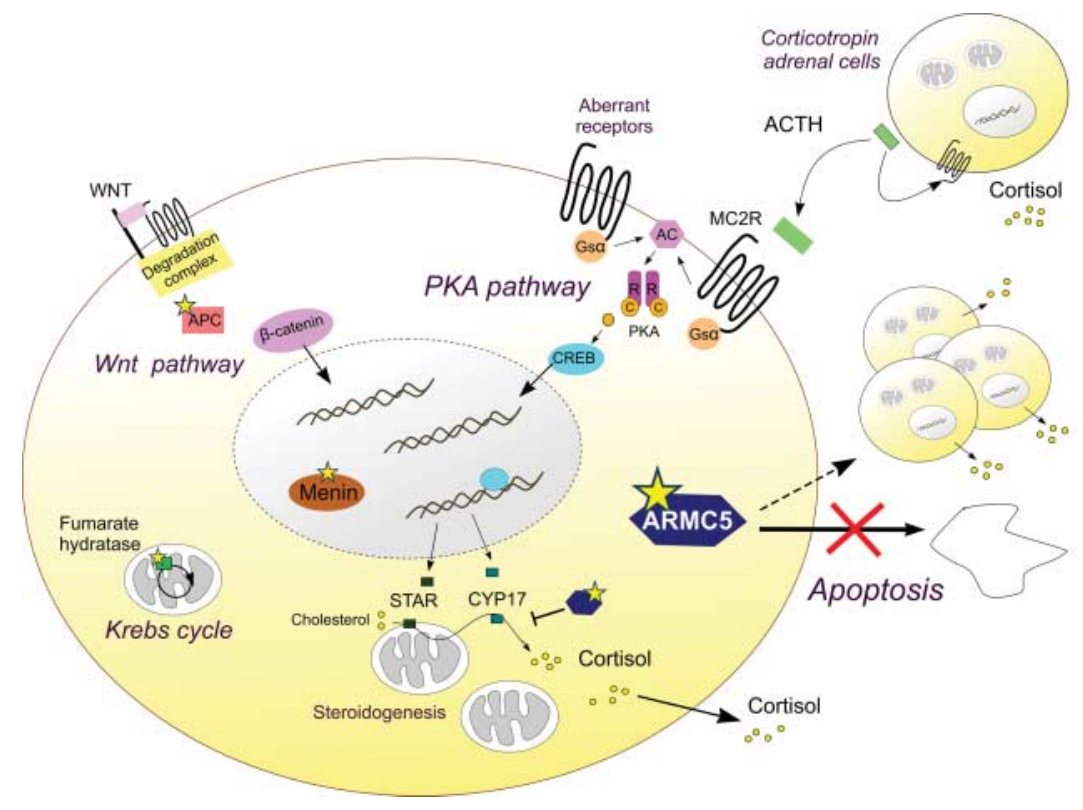

\section{Figure 1}

Pathophysiology of Primary Bilateral Macronodular Adrenal Hyperplasia (PBMAH). Mutations of proteins are represented by stars. Corticotropin adrenal cells: a cluster of gonadal-like adrenal cells secreting local ACTH responsible for an autocrine or paracrine stimulation of the PKA pathway. Aberrant receptors: the abnormal expression of ectopic or eutopic receptors leading to an activation of the PKA pathway in response to the corresponding stimuli. PKA pathway: other mechanisms leading to an activation of the PKA signaling pathway have been described. Wnt pathway: the Wnt/ $\beta$-catenin signaling pathway is involved in adrenocortical tumors. Mutations of APC in PBMAH lead to dissociation of the $\beta$-catenin from the destruction complex. The $\beta$-catenin protein accumulates in the cytoplasm and in the nucleus where it stimulates target gene expression. Krebs cycle: mutations of fumarate hydratase $(F H)$ suggest the involvement of the Krebs cycle in PBMAH. Steroidogenesis: steroidogenesis is paradoxically less efficient in PBMAH cells. Steroidogenic enzymes expression is decreased after ARMC5 inactivation. Apoptosis: The mutations of $A R M C 5$ lead to a decreased apoptosis of the adrenocortical cells and probably to their accumulation, explaining the increase of cortisol secretion despite a reduction of cortisol production at the cell level. 
of cortisol excess, a significant morbidity persists and that even in cured patients life expectancy is reduced $(12,13,14)$. Duration of cortisol excess, especially before CS diagnosis, is probably an important factor to reduce as far as possible for improvement of the recovery after cure of cortisol excess (15). Considering the rarity of CS and the difficulties for its screening and diagnosis by nonspecialized physicians, this is challenging. Endocrine tumors of genetic origin offer a good opportunity for early diagnosis by familial screening.

Several observations argue for a genetic origin of the PBMAH: the report of rare familial forms and the bilateral and multifocal characteristics of the adrenal nodules. Candidate gene approaches showed that actors of the cAMP/protein kinase A (PKA) signaling pathway or genes causing an hereditary familial tumor syndrome including adenomatous polyposis coli gene (APC), menin (MEN1) and fumarate hydratase $(F H)$ can favor or be responsible for the development of PBMAH (Fig. 1 and Table 1). Recently, the use of combined pan-genomic approaches led to the identification of a new gene, ARMC5, as a frequent cause of sporadic or familial PBMAH (16). This demonstrates that PBMAH is often genetically determined and brought some new perspectives for early diagnosis of the disease.

\section{Alterations in the CAMP/PKA signaling pathway in $\mathrm{PBMAH}$}

Stimulation of the PKA pathway by adrenocorticotropin (ACTH) is essential for the adrenal cortex maintenance and the synthesis and secretion of glucocorticoids and adrenal androgens (Fig. 2A). Various molecular and cellular alterations of the cAMP pathway have been described in adrenal tumors, including PBMAH (17). Activation of the PKA pathway by aberrant expression of G-protein-coupled receptors (GPCR) was one of the first mechanisms described in PBMAH (18) (Fig. 1). An abnormal expression of ectopic receptors (i.e., receptors that are not present on the surface of a normal adrenocortical cells) or eutopic receptors (i.e., normally present in an adrenocortical cells) leads to the activation of the PKA pathway in response to their corresponding stimulus (Fig. 2B) (18). However, to date, no genetics mechanisms enable to explain these abnormal expressions. The observation that some molecular defects as ARMC5 mutations (see below) seems to be associated with particular profile of GPCR expression suggests that it could be indirectly the consequence of primary genetic alterations not present on the respective gene of these receptors nor a component of its signaling pathway (16). Association of rare variants of the PDE11A and encoding the isoform $11 \mathrm{~A}$ of the phosphodiesterase enzyme with PBMAH have been observed $(19,20)$. PDE11A probably plays a role in the development of the disease by altering cAMP degradation. However, it is not per se a causal gene. Finally, only rare mutations of the melanocortin receptors type 2 gene $(M C 2 R)$ and of the guanine nucleotidebinding protein, alpha-stimulating activity polypeptide gene (GNAS), as well as the duplication of the catalytic subunit alpha of the PKA (PRKACA) have been described in PBMAH. They are all predicted to over-activate the PKA

Table 1 Genes identified in PBMAH.

\begin{tabular}{|c|c|c|c|}
\hline Gene & Locus & Function of the WT protein & Associated manifestations \\
\hline$A R M C 5$ & $16 p 11$ & $\begin{array}{l}\text { No known function, potential role in regulation } \\
\text { of apoptosis and steroidogenesis }\end{array}$ & Meningioma? \\
\hline Menin & $11 q 13$ & $\begin{array}{l}\text { Regulator of gene transcription, cell proliferation, } \\
\text { apoptosis, and genome stability }\end{array}$ & $\begin{array}{l}\text { Multiple endocrine neoplasia type } 1 \text { (MEN1): } \\
\text { hyperparathyroidism, pituitary adenomas, } \\
\text { pancreatic neuroendocrine tumors }\end{array}$ \\
\hline $\mathrm{FH}$ & $1 q 42$ & Krebs cycle, amino acid metabolism & $\begin{array}{l}\text { Hereditary leiomyomatosis and renal cell } \\
\text { carcinoma (HLRCC) }\end{array}$ \\
\hline PDE11A & $2 q 31-35$ & Hydrolysis of CAMP and cGMP & Isolated \\
\hline GNAS1 & $20 q 13$ & $\begin{array}{l}\text { Stimulation of adenyl cyclase, activation of the } \\
\text { CAMP/PKA pathway }\end{array}$ & $\begin{array}{l}\text { McCune Albright syndrome: fibrous bone dysplasia, } \\
\text { café-au-lait spots, precocious puberty, } \\
\text { acromegaly, toxic multinodular goiter }\end{array}$ \\
\hline$A P C$ & $5 q 12-22$ & $\begin{array}{l}\text { Prevent } \beta \text {-catenin accumulation, inhibition of the } \\
\text { Wnt/ } \beta \text {-catenin pathway }\end{array}$ & $\begin{array}{l}\text { Familial adenomatous polyposis: colon adenomas } \\
\text { and carcinomas, pigmented retinal lesions, } \\
\text { desmoids tumors, other malignant tumors as } \\
\text { adrenocortical carcinomas }\end{array}$ \\
\hline$M C 2 R$ & $18 p 11$ & $\begin{array}{l}\text { ACTH receptor, activation of the CAMP/PKA } \\
\text { pathway }\end{array}$ & Isolated \\
\hline$P R K A C A$ & $19 p 13.1$ & $\begin{array}{l}\text { Catalytic subunit of PKA, activation of the } \\
\text { CAMP/PKA pathway }\end{array}$ & \\
\hline
\end{tabular}



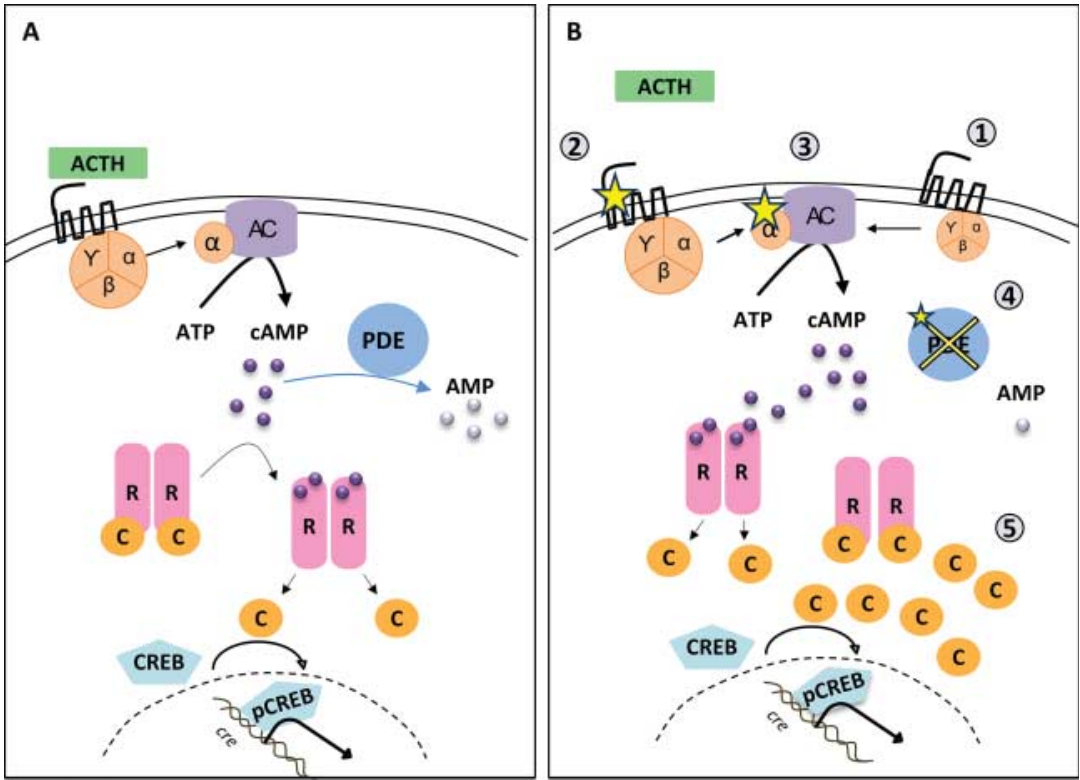

\section{Figure 2}

Activation of the PKA pathway in PBMAH. (A) Physiology of the CAMP/PKA signaling pathway from the cell surface to the nucleus in adrenocortical cells: in normal adrenocortical cells, the ACTH binds to MC2R resulting in the activation of the Gs protein. Then the activated subunit alpha stimulates adenylyl cyclase (AC), which produces CAMP. Four cAMP molecules bind to the dimer of regulatory subunits $(R)$ that set free catalytic subunits (C). Free catalytic subunits phosphorylate the transcription factor CREB which then activate the transcription of CAMP-regulated (CRE) genes. The phosphodiesterases (PDE) regulate the pathway by degrading the CAMP. (B) Dysregulation

pathway, but they have been observed in a limited number of patients.

ACTH binds its receptor, the G-protein-coupled melanocortin 2 receptor (MC2R), and activates the PKA pathway (Fig. 2A). Mutation in MC2R is a rare event (21), described in two reports only $(22,23)$. In the first one, a patient presenting with episodic cortisol excess and PBMAH harbored the germline mutation F278C leading in vitro to an increase of the accumulation of cAMP and the activation of the PKA after stimulation by ACTH (22) (Fig. 2B). The second one concerns a patient carrying two pathogenic variants in the same allele but without PBMAH (23).

The guanine nucleotide-binding protein, alphastimulating activity polypeptide (GNAS) gene encodes for the subunit alpha of the $G$ protein. $G$ protein couples hormone receptors to adenylyl cyclase and leads, via the stimulation of this enzyme, to the production of cAMP of the CAMP/PKA signaling pathway in Cushing's syndrome: several molecular alterations of components of the CAMP/PKA signaling pathway have been described in PBMAH: i) aberrant expression of GPCR leading to a specific activation of the PKA pathway depending on the receptor and its ligand; ii) activating mutation of $M C 2 R$ leading to higher activation of the pathway when stimulated by $A C T H$, iii) activating mutations of GNAS; iv) inactivating mutations of $P D E 11 A$ leading to an accumulation of (AMP, v) duplication of the PRKACA gene leading to an accumulation of the PKA catalytic subunits alpha.

(Fig. 2A). Post-zygotic mutations of GNAS have been reported in a patient with McCune Albright syndrome (24). This disease is characterized by a congenital polyostotic fibrous bone dysplasia, the presence of café-au-lait skin spot and precocious puberty. Neonatal CS by nodular adrenal hyperplasia could also occur (24). Beside early postzygotic events, somatic mutations of GNAS in adrenal nodules of patients with PBMAH have been described in few patients $(10,25,26)$. Two mutants were described, R201H $(10,25,26)$ and R201S (25), and their deleterious effect were proved in GH-producing pituitary tumors. Substitutions occurring in the arginine 201 led to an activation of cAMP formation, by inhibition of the intrinsic GTPase activity of the G-protein alpha subunit. GNAS defects in adult PBMAH patients are also a rare event (27).

In 2014, somatic activating mutation of PRKACA, coding for the catalytic subunit alpha of PKA, has been 
discovered by whole exome cequencing (WES) as a frequent cause of overt-cortisol producing adenomas, observed in $40 \%$ of such unilateral tumors $(17,28)$. To date, no germline mutation of PRKACA has been described $(17,29)$. However, germline duplications on a genomic region on chromosome 19 including PRKACA were found in PBMAH patients $(28,30)$ (Fig. 2B). Three cases have been reported so far: a mother and her son who presented mild insidious CS due to PBMAH diagnosed at the third and fourth decade respectively (28); the third one was a 2-year-old boy operated for PBMAH. In this last case, the PBMAH was associated with neonatal hypoglycemia and macroglossia (30). Further studies are needed to determine the frequency of PRKACA duplication in large cohorts of PBMAH patients.

\section{Multiple tumors syndromes associated with PBMAH}

Familial adenomatous polyposis coli and mutations of APC - Activation of the Wnt/ $\beta$-catenin signaling pathway is involved in adrenal tumors, especially non-cortisolproducing adenomas and adrenocortical carcinomas (31). Patients with familial adenomatous polyposis (FAP) (OMIM \#175100) present multiple colonic polyps and an increased risk of early colon carcinomas and various adrenocortical tumors, including non-functional cortisol producing adenoma, adrenocortical cancer (31) and bilateral macronodular adrenal hyperplasia $(10,32)$. FAP is caused by germline inactivating mutation of $A P C$ (5q22), a tumor suppressor gene that inhibits Wnt/ $\beta$-catenin signaling. In the tumor tissue, the second allele is inactivated by a second event, a mutation (32) or a loss of heterozygosity ( $\mathrm{LOH}$ ) of the APC locus (33) (Fig. 3A). Interestingly, the second event differs in function of the nodules in the patient with PBMAH (32). The role of the activation of $\beta$-catenin as a driver of adrenocortical tumorigenesis has been clearly demonstrated in vitro and in vivo (31).

Multiple endocrine neoplasia type $1>$ Germline inactivating alterations of the MEN1 gene (11q13) cause multiple endocrine neoplasia type 1 , characterized by development of endocrine or non-endocrine tumors (OMIM \#131100). The most frequent features are primary hyperparathyroidism, pancreatic endocrine tumors and pituitary adenomas. Adrenal lesions have been described and vary: either bilateral or unilateral, including adrenal enlargement, adenomas, macronodular adrenal hyperplasia and adrenal cancer. The frequency of adrenal lesions range between 9 and $73 \%$ depending on the screening methods used (34).
Bilateral lesions represent almost half of the patients with adrenal abnormalities. Recently, a retrospective analysis of the French and Belgium multicenter database (Groupe d'étude des Tumeurs Endocrines) including 715 MEN1 patients reported adrenal enlargement in $20.4 \%$ of the patients (34). Patients with bilateral tumors represented only $1.3 \%$ of the total cohort. Interestingly, the frequency

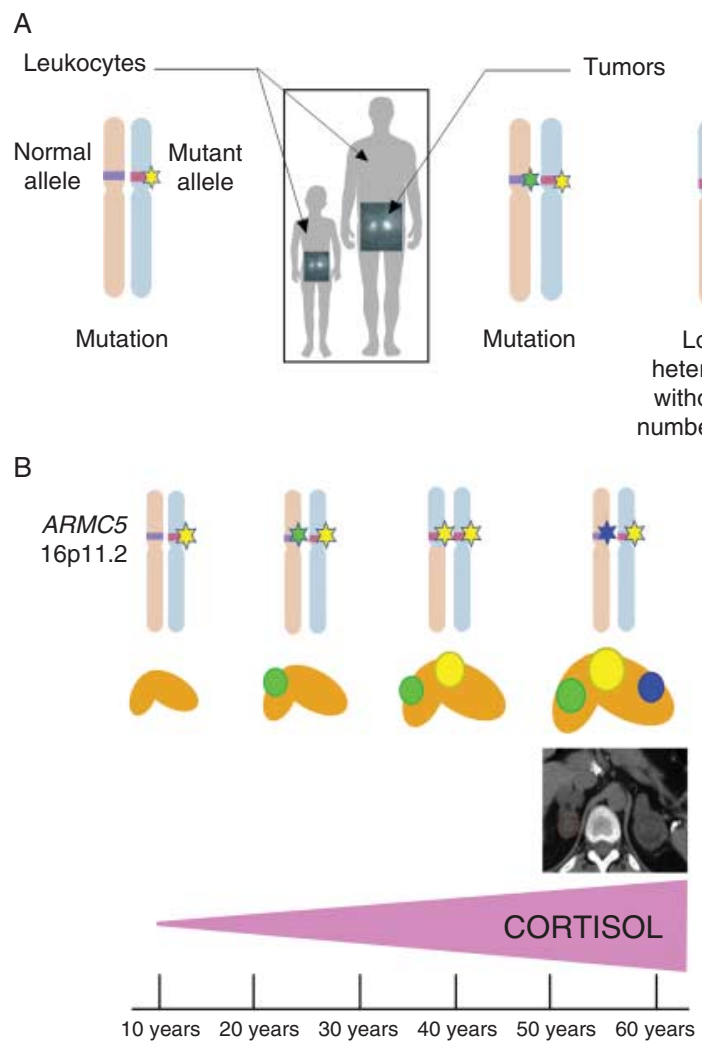

\section{Figure 3}

Model of bi-allelic inactivation of a tumor suppressor gene in Primary Bilateral Macronodular Adrenal Hyperplasia (PBMAH) development. (A) For a complete loss-of-function, the inactivation of a tumor suppressor gene has to inactivate both alleles. According to the Knudson model it is occurring by a two steps mechanism. First, a germline event inactivates the first allele. Latter a somatic inactivation of the second allele by either a $\mathrm{LOH}$ or a second mutation (represented by stars) leads to the development of the nodules. (B) In a patient with a germline ARMC5 mutation a secondary somatic alterations (16p LOH without copy number change or mutation) occur latter in various adrenocortical cells on both side. This leads to the slow development of adrenal macronodules. Most often the diagnosis is made between the age of 50 and 60 years, typically after investigation of an incidentaloma or clinical signs of Cushing's syndrome progressing for several years. 
of CS was higher than observed for adrenal incidentalomas. In particular, one of the patients with CS had bilateral tumors compatible with a PBMAH. MEN1 is a tumor suppressor gene involved in cellular functions as cell cycle and proliferation (35). Knockout mice with deletion of certain exons developed adrenal tumors or hyperplasia that could be bilateral or associated with corticosterone secretion (36). Finally, PBMAH could be considered as one of the manifestations of MEN1. Clinical and biological signs of CS must be attentively seek in MEN1 patients with bilateral adrenal lesions.

Fumarate hydratase - Autosomal dominant inactivating mutation of the fumarate hydratase (FH) gene (1q43) causes hereditary leiomyomatosis and renal cell carcinoma (HLRCC) (OMIM \# 150800). FH is an enzyme that converts fumarate to malate during the Krebs cycle. The frequency of adrenal lesions in HLRCC has been estimated to $7.8 \%$ in a series of 255 patients. The nodules were multifocal and bilateral in 20\% (four patients) and 15\% (three patients) respectively (37). Only one of the three patients with bilateral lesions presented a clinical CS $(37,38)$. In this patient, a $\mathrm{LOH}$ occurred in the adrenal lesions leading to a bi-allelic inactivation of the gene (Fig. 3A) (38). Thus, if the frequency of PBMAH among patients with HLRCC is low, it could be considered as a cause of PBMAH.

\section{Armadillo repeat containing 5, the main genetic cause of PBMAH}

Identification of ARMC5 as a new tumor suppressor gene in PBMAH - Before 2013, all genetic defects described in PBMAH and resumed above explained only a few cases. However, the bilateral character and the multifocal nodules of the adrenal disease, as well as the report of few cases of familial PBMAH, suggests a major role of genetic factors in PBMAH development. In keeping with this hypothesis, we reported in 2013 the identification of a new gene responsible for PBMAH using an integrated genomics approach (16). The analysis of a series of adrenal tumor tissues from 33 PBMAH patients by single-nucleotide polymorphism (SNP) array identified the copy-neutral $\mathrm{LOH}$ at chromosome $16 \mathrm{p}$ as the most frequent chromosomal alteration. This $16 \mathrm{p} \mathrm{LOH}$ was found in the tumor tissue from a quarter of the patients. Then, using whole genome sequencing of paired germlinesomatic DNA, germline and somatic inactivating mutations in the armadillo repeat containing 5 (ARMC5) gene were discovered. The ARMC5 gene is located at chromosome 16p11.2. For the analysis of tumor and leucocyte DNA it appear that the germline ARMC5 alteration is detected in all the adrenal nodules in an ARMC5 mutated patient, whereas the somatic alteration differ for each adrenal nodule (16). The latter is a somatic mutation in $68 \%$ of the nodules or a $\mathrm{LOH}$ at $16 \mathrm{p}$ in $32 \%$ (39). These characteristics are those of a tumor suppressor gene (Fig. 3A). In this first series of operated PBMAH patients, ARMC5 germline mutations or deletions were observed in $55 \%$ of the cases. This clearly established that PBMAH is frequently of genetic origin in adults, even in the absence of a multiple tumor syndrome. Subsequently, two studies have confirmed that ARMC5 mutations are frequent in PBMAH. ARMC5 mutations were reported in almost $25 \%$ of PBMAH index cases in theses series, which include operated as well as non-operated patients $(9,40)$.

ARMC5 mutations and phenotype in PBMAH $\rightarrow$ The first studies by Assié et al. (16) and Faucz et al. (9) suggested that ARMC5 defects are associated with a more severe disease. This was confirmed by a recent European study on 98 index cases PBMAH patients with different severities of Cushing's syndrome (39). Twenty-five percent of these index case patients presented with an ARMC5 defect, and mutated patients had higher cortisol levels, larger adrenal glands and higher numbers of nodules on computed tomography (CT)-scan. They were also more often operated than non-mutated patients. Interestingly, mutated patients did not present a cortisol response to food ingestion, suggesting the association of ARMC5 mutation with specific patterns of illegitimate receptors. Another interesting observation is that ARMC5-mutated patients have hypertension more often than WT patients. A more severe hypercortisolism is probably one of the major explanations, but it has been recently suggested that ARMC5 mutation could favor hypertension with low renin hyperaldosteronism in the African-American population (41). The investigation of a cohort of 56 patients with primary hyperaldosteronism showed $10.7 \%$ of ARMC5 variants predicted pathogenic by in silico analysis in African-American patients. Two of these patients had bilateral adrenal hyperplasia and co-secretion of aldosterone and cortisol (41). Whether this applies to other populations remains to be demonstrated.

Three recent studies demonstrate that ARMC5 mutation is a very frequent cause of clear familial forms of PBMAH. These studies included PBMAH patients with relatives clearly diagnosed with the disease and presenting frequently a Cushing's syndrome on the basis of investigations done before any genetic screen. In eight out of the ten large families reported so far, an ARMC5 germline 
mutation could be found (40, 42, 43). Alencar et al. (40) investigated 47 patients from a large Brazilian PBMAH family on up to three generations and found a germline mutation in all 16 affected members. The sporadic cases are more frequently reported than familial cases but the familial nature of the disease is probably underestimated because of the phenotypic variability. Subclinical forms of Cushing's syndrome are underdiagnosed if a systematic familial screen is not performed. This is supported by familial studies demonstrating that in some of the ARMC5 adults mutation carriers identified by familial screening the adrenal alterations are subtle (40). With the data already published, it seems that the penetrance of the disease is very high in adults who are mutation carriers. Indeed, almost all of them present adrenal imaging and/or hormonal alterations $(15,39)$. However, the severity of the disease might vary and some relatives of the index cases can present with only CT-scan alterations of sub-clinical Cushing's.

Combining all the ARMC5 studies reported to date, a total of 29 germline and 32 somatic pathogenic mutations have been identified $(9,16,39,40,41,42,43)$ (Fig. 4). Two additional mutations were identified in tumor DNA but the germline or somatic origin was not determinate (39). Among these mutations, a few of them can be found in non-related index cases, as the germline mutations p.I58Nfs44* $(9,40)$, p.R267X $(9,16,39)$, p.R593W $(9,42)$, p.R898W $(9,16,39)$ and the p.A106Rfs31* $(39,43)$. The ARMC5 mutations are spread equally along the sequence. This multitude of described mutations suggests that most of the pathogenic mutations are private and that there is no clear hot spot for ARMC5 mutations.

It remains to be established whether ARMC5 can be responsible for a broader tumor predisposition syndrome as observed in MEN1, FAP and McCune-Albright syndrome. Indeed, two studies described occurrence of meningiomas in several ARMC5-mutated patients $(40,43)$. In one of these study, Elbelt et al. brought strong evidence for the involvement of ARMC5 in meningioma development by the description of a somatic ARMC5 mutation in the DNA from the meningioma tumor. For this 69-year-old woman, several different mutations were found in her adrenal nodules (43). In the second study, Alencar et al. reported the co-occurrence of meningioma in three out of seven members $(43 \%)$ of the same family with macronodular adrenal hyperplasia due to ARMC5 mutation. The authors suggest that the ARMC5 gene will be a causal gene in both PBMAH and meningioma.

Function of ARMC5 and its implication in PBMAH development $>$ The initiation and development mechanisms of PBMAH are not explained, but the discovery of the involvement of ARMC5 alterations opens new research perspectives. The understanding of the role of ARMC5 is essential for a better characterization of the molecular mechanisms involved in the disease. However, to date, very little is known about ARMC5 structure or function. It is very difficult to predict the biological role of the ARMC5 protein from its peptidic sequence. It has been termed after its sequence homology with other members of the ARMC family of proteins. All the members of this family contain two domains involved in proteins-proteins interaction: the armadillo repeat domains (ARM repeat) and the BTB/POZ (broad complex Tramtrack bric-a-brac/Pox virus and zinc finger) (Fig. 4A). These two domains are highly conserved during evolution from drosophila to human. Despite the presence of these domains, it is not possible to predict the partners of the ARMC5 protein because the recognition mechanism of these domains with substrate and/or target proteins is not fully characterized. However, the existence of these domains suggests that ARMC5 can interact with various proteins, and by doing so be involved in several biological processes.

Inactivation of ARMC5 in PBMAH follows the 'two-hit' model of a tumor suppressor gene responsible for a hereditary neoplasia syndrome. Tumor suppressor genes are known to control cell proliferation in order to limit clonal cell expansion. Inactivating mutations lead to either the expression of an inactive mutant protein or the absence of the protein. In the case of ARMC5, the model suggests that the loss of cell control in the adrenal cortex secondary to ARMC5 mutation leads to nodular hyperplasia development. Initial studies showed two potential roles of ARMC5 that could be important for PBMAH development. On one hand, the transient overexpression of the normal ARMC5 protein induces early cell death in human adrenocortical cells, while ARMC5 missense mutants lose the ability to induce apoptosis. On the other hand, in adrenocortical cells the expression of various major actors of steroidogenesis is altered following the in vitro inactivation of ARMC5 expression by siRNA (Fig. 1). Indeed, the levels of the mRNA of the MC2R receptor, the transcription factor SF1 and the steroidogenic enzymes CYP17 and CYP21 are lower in ARMC5-deficient cells. This is observed both in basal condition and after stimulation of the cAMP production by forskolin. The decreased expression of several actors of the steroidogenic cascade induces a decrease of cortisol production (16). In view of the ARMC5 protein sequence, it could be suggested that ARMC5 possibly interacts with proteins regulating the 
A n
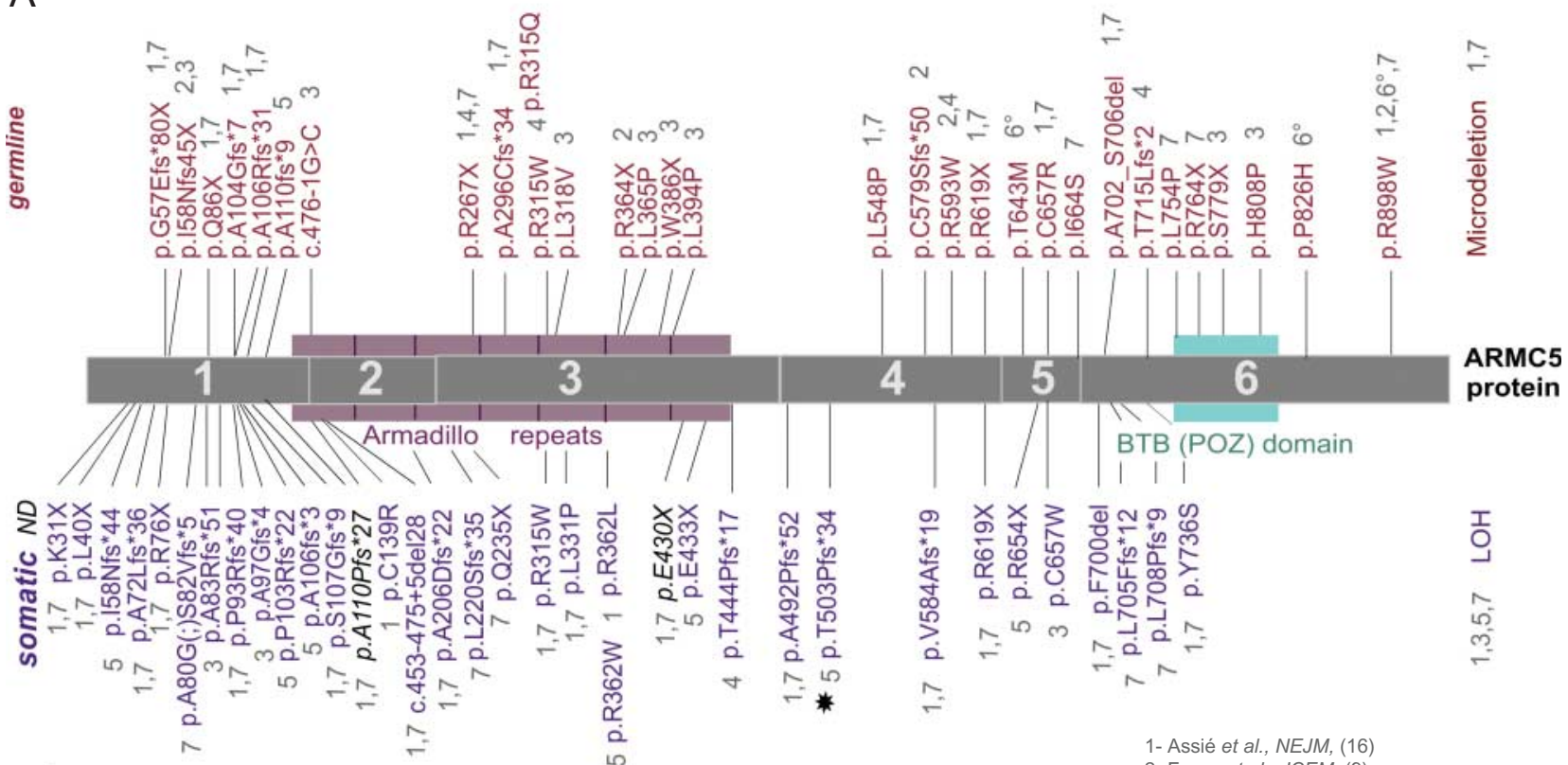

* Meningioma

- Described in patient with hyperaldosteronism

- Assié et al, NEJM, (16)

3- Alencar et al., JCEM, (40)

4- Gagliardi et al., JCEM, (42)

5- Elbelt et al., JCEM, (43)

6- Zilbermint et al., JCEM, (41)

7- Espiard et al., JCEM, (39)

B

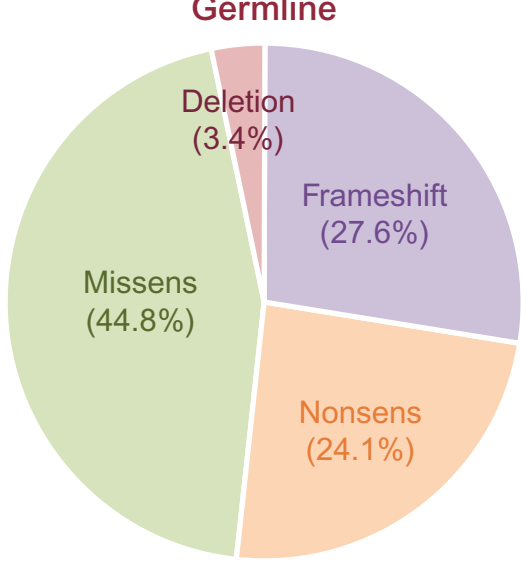

Somatic

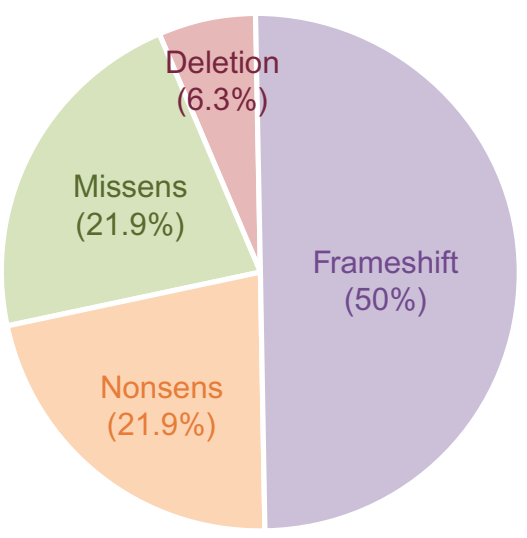

Total

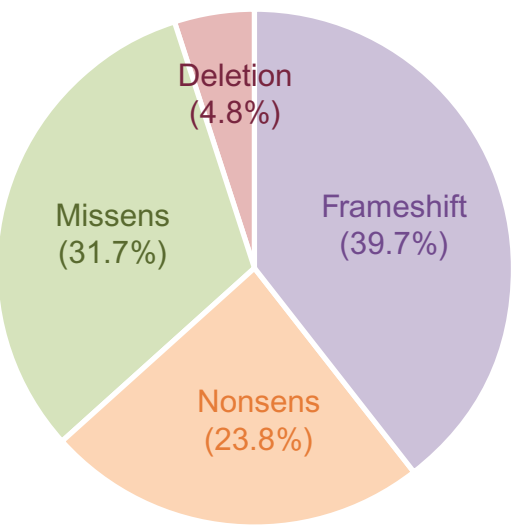

\section{Figure 4}

Locations and frequency of $A R M C 5$ mutations identified in patients with Primary Bilateral Macronodular Adrenal Hyperplasia (PBMAH). (A) In the upper part of the ARMC5 sequence are shown germline mutations (written in red) and in the lower part of the ARMC5 sequence somatic mutations (written in purple) and non-determinate (written in black italic, ND) mutations. *indicates mutations identified in meningioma, indicates mutations identified in patients with primary hyperaldosteronism. (B) The diagrams show the frequency of each type (frameshift, deletion, missense, and nonsense) of mutations identified on germline DNA (left), or tumor DNA (somatic) (center) or the cumulative description of all the identified mutations (right). 
apoptosis and steroidogenic processes. Dissemination of mutations along the gene in PBMAH patients suggests that most of the mutations could lead to a conformational change of the ARMC5 protein and so disrupt interaction with different partners and function. Further studies will be important to understand the exact role of this protein in these two cellular processes, in order to know how ARMC5 is involved in the initiation and/or development of PBMAH. The understanding of the ARMC5 protein interaction network will provide a genome-scale resource for elucidating normal functions of ARMC5, other pathogenic mechanisms of ARMC5 mutant forms, as well as deeper mechanistic insights into known signaling pathways altered in PBMAH (for instance, the cAMP pathway).

In PBMAH patients with ARMC5 mutation, CT scans show multiple macronodules that are more numerous than in WT patients (39). Similarly, the adrenal weight from operated patients is higher in ARMC5-mutated patients. Considering the in vitro data obtained on ARMC5 function, this would suggest that adrenal hyperplasia and nodules appear progressively due to decreased apoptosis following ARMC5 inactivation. At the same time, tumor cell differentiation is responsible for a lower but pituitary-autonomous cortisol synthesis and secretion capacity by each adrenal cell. When the adrenal mass is large enough, the balance between steroidogenesis capacity and cortisol autonomy results in cortisol excess (Fig. 3B). This process takes years to develop since PBMAH is a benign tumor probably with a very slow growth rate. This would explain why Cushing's syndrome in PBMAH patients is most often diagnosed late in adult life.

\section{Perspectives in the genetic of PBMAH}

Despite ARMC5 being the first gene discovered to be frequently involved in PBMAH, three-quarters of all PBMAH adult patients non-selected on the basis of the severity of Cushing's syndrome nor familial history are apparently not explained. If PBMAH in these patients is also of genetic origin, the causal gene(s) remains to be identified. Pan-genomic studies, especially WES, are powerful tools to advance in the understanding of the genetics of PBMAH and identify new candidate genes. Considering our first whole genome sequencing study (16) and studies reported by others using WES $(43,44,45)$, it is likely that either each of the other genes will be implicated in a small subset of patients or that a large portion of remaining patients do not have a single monogenic disorder. Recently, another WES study from China in patients with various types of adrenocortical tumors, including PBMAH, has suggested new candidate genes. Somatic mutations of DOT1-like histone H3K79 methyltransferase gene $(D O T 1 L)$ were reported in two out of seven PBMAH. DOT1L encodes for a histone H3 lysine methyltransferase with important cellular functions, as regulation of gene transcription and cellular proliferation. In this cohort, a PBMAH presented with a mutation in the histone deacetylase 9 gene (HDAC9) (44). A variant (S420T) in the endothelin receptor type A gene (EDNRA) was identified by WES and discussed as a potential cause in two patients from the same family and one sporadic case (45). EDNRA encodes for the GPCR endothelin receptor type A, involved in cardiovascular or polycystic kidney disease. Sequencing of large cohorts of patients and functional studies are needed to confirm the involvement of this gene in PBMAH (45). It is also likely that future pangenomic studies will suggest new PBMAH candidate genes. In the likely hypothesis that PBMAH could be a heterogeneous disease, integrated genomic characterization of PBMAH as performed recently in adrenocortical carcinomas could lead to a better molecular classification of PBMAH (16) that might help in the identification of new causative gene(s).

\section{Conclusion}

Major advances in the genetics of PBMAH have been possible the past 3 years with the use of pan-genomic approaches. These advances open new perspectives for understanding the pathophysiology of the disease. The knowledge of ARMC5 functions could help understand PBMAH development.

Already, genetic screening for ARMC5 germline mutation could help better diagnose and classify patients with PBMAH. Familial screening would lead to the identification of the relatives of an index case with ARMC5 mutation at risk of Cushing's syndrome development. Prospective follow-up will allow a better analysis of the development of PBMAH in such families. How this would translate into early cures or even prevention of Cushing's syndrome, and how this would improve the long-term manifestations of cortisol excess, is an exciting question that can now be addressed.

\footnotetext{
Declaration of interest
}

The authors declare that there is no conflict of interest that could be perceived as prejudicing the impartiality of the review. 
Funding

This research did not receive any specific grant from any funding agency in the public, commercial or not-for-profit sector.

\section{Acknowledgements}

Our studies on this subject are supported in part by the Institut National de la Santé et de la Recherche Médicale (S Espiard is receiving a 'Poste Accueil' fellowship grant), the E-RARE program (Genomics of CAMP signaling alterations in adrenal Cushing project), the Conny-Maeva Charitable Foundation ( $L$ Drougat is receiving a fellowship grant), and the Brou de Laurière foundation.

This paper forms part of a special issue of European Journal of Endocrinology on Cushing's syndrome. This article is adapted from work presented at the IMPROCUSH-1: Improving Outcome of Cushing's Syndrome symposium, 12-14 October 2014. The meeting was supported by the European Science Foundation, Deutsche Forschungsgemeinschaft, Carl Friedrich von Siemens Stiftung, European Neuroendocrine Association and the Deutsche Gesellschaft für Endokrinologie. The opinions or views expressed in this special issue are those of the authors, and do not necessarily reflect the opinions or recommendations of the European Science Foundation, Deutsche Forschungsgemeinschaft, Carl Friedrich von Siemens Stiftung, European Neuroendocrine Association and the Deutsche Gesellschaft fur Endokrinologie.

\section{References}

1 Lacroix A. ACTH-independent macronodular adrenal hyperplasia. Best Practice \& Research. Clinical Endocrinology \& Metabolism 200923 245-259. (doi:10.1016/j.beem.2008.10.011)

2 Louiset E, Duparc C, Young J, Renouf S, Tetsi Nomigni M, Boutelet I, Libé R, Bram Z, Groussin L, Caron P et al. Intraadrenal corticotropin in bilateral macronodular adrenal hyperplasia. New England Journal of Medicine 2013369 2115-2125. (doi:10.1056/NEJMoa1215245)

3 Lacroix A. Heredity and cortisol regulation in bilateral macronodular adrenal hyperplasia. New England Journal of Medicine 2013369 2147-2149. (doi:10.1056/NEJMe1312792)

4 Reznik Y, Allali-Zerah V, Chayvialle JA, Leroyer R, Leymarie P, Travert G, Lebrethon MC, Budi I, Balliere AM \& Mahoudeau J. Food-dependent Cushing's syndrome mediated by aberrant adrenal sensitivity to gastric inhibitory polypeptide. New England Journal of Medicine 1992327 981-986. (doi:10.1056/NEJM199210013271403)

5 Lacroix A, Bolté E, Tremblay J, Dupré J, Poitras P, Fournier H, Garon J, Garrel D, Bayard F \& Taillefer R. Gastric inhibitory polypeptidedependent cortisol hypersecretion - a new cause of Cushing's syndrome. New England Journal of Medicine 1992327 974-980. (doi:10.1056/NEJM199210013271402)

6 Groussin L, Perlemoine K, Contesse V, Lefebvre H, Tabarin A, Thieblot P, Schlienger JL, Luton JP, Bertagna X \& Bertherat J. The ectopic expression of the gastric inhibitory polypeptide receptor is frequent in adrenocorticotropin-independent bilateral macronodular adrenal hyperplasia, but rare in unilateral tumors. Journal of Clinical Endocrinology and Metabolism 200287 1980-1985. (doi:10.1210/jcem.87.5.8458)

7 Vassilatou E, Vryonidou A, Ioannidis D, Paschou SA, Panagou M \& Tzavara I. Bilateral adrenal incidentalomas differ from unilateral adrenal incidentalomas in subclinical cortisol hypersecretion but not in potential clinical implications. European Journal of Endocrinology/ European Federation of Endocrine Societies 2014171 37-45. (doi:10.1530/EJE-13-0848)

8 Barzon L, Sonino N, Fallo F, Palu G \& Boscaro M. Prevalence and natural history of adrenal incidentalomas. European Journal of Endocrinology/European Federation of Endocrine Societies 2003149 273-285. (doi:10.1530/eje.0.1490273)
9 Faucz FR, Zilbermint M, Lodish MB, Szarek E, Trivellin G, Sinaii N, Berthon A, Libé R, Assié G, Espiard S et al. Macronodular adrenal hyperplasia due to mutations in an armadillo repeat containing 5 (ARMC5) gene: a clinical and genetic investigation. Journal of Clinical Endocrinology and Metabolism 201499 E1113-E1119. (doi:10.1210/ jc.2013-4280)

10 Hsiao H-P, Kirschner LS, Bourdeau I, Keil MF, Boikos SA, Verma S, Robinson-White AJ, Nesterova M, Lacroix A \& Stratakis CA. Clinical and genetic heterogeneity, overlap with other tumor syndromes, and atypical glucocorticoid hormone secretion in adrenocorticotropinindependent macronodular adrenal hyperplasia compared with other adrenocortical tumors. Journal of Clinical Endocrinology and Metabolism 200994 2930-2937. (doi:10.1210/jc.2009-0516)

11 Libé R, Coste J, Guignat L, Tissier F, Lefebvre H, Barrande G, Ajzenberg C, Tauveron I, Clauser E, Dousset B et al. Aberrant cortisol regulations in bilateral macronodular adrenal hyperplasia: a frequent finding in a prospective study of 32 patients with overt or subclinical Cushing's syndrome. European Journal of Endocrinology 2010163 129-138. (doi:10.1530/EJE-10-0195)

12 Barahona M-J, Resmini E, Viladés D, Pons-Lladó G, Leta R, Puig T \& Webb SM. Coronary artery disease detected by multislice computed tomography in patients after long-term cure of Cushing's syndrome. Journal of Clinical Endocrinology and Metabolism 201398 1093-1099. (doi:10.1210/jc.2012-3547)

13 Van Haalen FM, Broersen LHA, Jorgensen JO, Pereira AM \& Dekkers OM. Management of endocrine disease: mortality remains increased in Cushing's disease despite biochemical remission: a systematic review and meta-analysis. European Journal of Endocrinology/European Federation of Endocrine Societies 2015172 R143-R149. (doi:10.1530/EJE-14-0556)

14 Wagenmakers MA, Netea-Maier RT, Prins JB, Dekkers T, den Heijer M \& Hermus AR. Impaired quality of life in patients in long-term remission of Cushing's syndrome of both adrenal and pituitary origin: a remaining effect of long-standing hypercortisolism? European Journal of Endocrinology/European Federation of Endocrine Societies 2012 167 687-695. (doi:10.1530/EJE-12-0308)

15 Lambert JK, Goldberg L, Fayngold S, Kostadinov J, Post KD \& Geer EB. Predictors of mortality and long-term outcomes in treated Cushing's disease: a study of 346 patients. Journal of Clinical Endocrinology and Metabolism 201398 1022-1030. (doi:10.1210/jc.2012-2893)

16 Assié G, Libé R, Espiard S, Rizk-Rabin M, Guimier A, Luscap W, Barreau $\mathrm{O}$, Lefèvre L, Sibony M, Guignat L et al. ARMC5 mutations in macronodular adrenal hyperplasia with Cushing's syndrome. New England Journal of Medicine 2013369 2105-2114. (doi:10.1056/NEJMoa1304603)

17 Espiard S, Ragazzon B \& Bertherat J. Protein kinase A alterations in adrenocortical tumors. Hormone and Metabolic Research 201446 2105-2114. (doi:10.1055/s-0034-1385908)

18 Lacroix A, Bourdeau I, Lampron A, Mazzuco TL, Tremblay J \& Hamet P. Aberrant G-protein coupled receptor expression in relation to adrenocortical overfunction. Clinical Endocrinology 201073 1-15. (doi:10.1111/j.1365-2265.2009.03689.x)

19 Libé R, Fratticci A, Coste J, Tissier F, Horvath A, Ragazzon B, RenéCorail F, Groussin L, Bertagna X, Raffin-Sanson ML et al. Phosphodiesterase $11 \mathrm{~A}(\mathrm{PDE} 11 \mathrm{~A})$ and genetic predisposition to adrenocortical tumors. Clinical Cancer Research 200814 4016-4024. (doi:10.1158/1078-0432)

20 Vezzosi D, Libé R, Baudry C, Rizk-Rabin M, Horvath A, Levy I, René-Corail F, Ragazzon B, Stratakis CA \& Bertherat J. Phosphodiesterase 11A (PDE11A) gene defects in patients with ACTH-independent macronodular adrenal hyperplasia (AIMAH): functional variants may contribute to genetic susceptibility of bilateral adrenal tumors. Journal of Clinical Endocrinology and Metabolism 201297 E2063-E2069. (doi:10.1210/jc.2012-2275)

21 Latronico AC, Reincke M, Mendonça BB, Arai K, Mora P, Allolio B, Wajchenberg BL, Chrousos GP \& Tsigos C. No evidence for oncogenic mutations in the adrenocorticotropin receptor gene in human 
adrenocortical neoplasms. Journal of Clinical Endocrinology and Metabolism 199580 875-877.

22 Swords FM, Baig A, Malchoff DM, Malchoff CD, Thorner MO, King PJ, Hunyady L \& Clark AJ. Impaired desensitization of a mutant adrenocorticotropin receptor associated with apparent constitutive activity. Molecular Endocrinology 2002 16 2746-2753. (doi:10.1210/me.2002-0099)

23 Swords FM, Noon LA, King PJ \& Clark AJ. Constitutive activation of the human ACTH receptor resulting from a synergistic interaction between two naturally occurring missense mutations in the MC2R gene. Molecular and Cellular Endocrinology 2004213 149-154. (doi:10.1016/ j.mce.2003.10.052)

24 Salpea P \& Stratakis CA. Carney complex and McCune Albright syndrome: an overview of clinical manifestations and human molecular genetics. Molecular and Cellular Endocrinology 2014386 85-91. (doi:10.1016/j.mce.2013.08.022)

25 Fragoso MC, Domenice S, Latronico AC, Martin RM, Pereira MA, Zerbini MC, Lucon AM \& Mendonca BB. Cushing's syndrome secondary to adrenocorticotropin-independent macronodular adrenocortical hyperplasia due to activating mutations of GNAS1 gene. Journal of Clinical Endocrinology and Metabolism 200388 2147-2151. (doi:10.1210/jc.2002-021362)

26 Almeida MQ, Azevedo MF, Xekouki P, Bimpaki EI, Horvath A, Collins MT, Karaviti LP, Jeha GS, Bhattacharyya N, Cheadle C et al. Activation of cyclic AMP signaling leads to different pathway alterations in lesions of the adrenal cortex caused by germline PRKAR1A defects versus those due to somatic GNAS mutations. Journal of Clinical Endocrinology and Metabolism 201297 E687-E693. (doi:10.1210/jc.2011-3000)

27 Lania AG, Mantovani G \& Spada A. Mechanisms of disease: mutations of $\mathrm{G}$ proteins and G-protein-coupled receptors in endocrine diseases. Nature Clinical Practice. Endocrinology \& Metabolism 20062 681-693. (doi:10.1038/ncpendmet0324)

28 Beuschlein F, Fassnacht M, Assié G, Calebiro D, Stratakis CA, Osswald A, Ronchi CL, Wieland T, Sbiera S, Faucz FR et al. Constitutive activation of PKA catalytic subunit in adrenal Cushing's syndrome. New England Journal of Medicine 2014370 1019-1028. (doi:10.1056/NEJMoa1310359)

29 Di Dalmazi G, Kisker C, Calebiro D, Mannelli M, Canu L, Arnaldi G, Quinkler M, Rayes N, Tabarin A, Laure Jullié M et al. Novel somatic mutations in the catalytic subunit of the protein kinase A as a cause of adrenal Cushing's syndrome: a European multicentric study. Journal of Clinical Endocrinology and Metabolism 201499 E2093-E2100. (doi:10.1210/jc.2014-2152)

30 Carney JA, Lyssikatos C, Lodish MB \& Stratakis CA. Germline PRKACA amplification leads to Cushing syndrome caused by 3 adrenocortical pathologic phenotypes. Human Pathology 201546 40-49. (doi:10.1016/ j.humpath.2014.09.005)

31 Berthon A, Drelon C, Ragazzon B, Boulkroun S, Tissier F, Amar L, Samson-Couterie B, Zennaro M-C, Plouin P-F, Skah S et al. WNT/ $\beta$-catenin signalling is activated in aldosterone-producing adenomas and controls aldosterone production. Human Molecular Genetics 2014 23 889-905. (doi:10.1093/hmg/ddt484)

32 Gaujoux S, Pinson S, Gimenez-Roqueplo A-P, Amar L, Ragazzon B, Launay P, Meatchi T, Libé R, Bertagna X, Audebourg A et al. Inactivation of the APC gene is constant in adrenocortical tumors from patients with familial adenomatous polyposis but not frequent in sporadic adrenocortical cancers. Clinical Cancer Research 201016 5133-5141. (doi:10.1158/1078-0432.CCR-10-1497)

33 Hosogi H, Nagayama S, Kanamoto N, Yoshizawa A, Suzuki T, Nakao K \& Sakai Y. Biallelic APC inactivation was responsible for functional adrenocortical adenoma in familial adenomatous polyposis with novel germline mutation of the APC gene: report of a case. Japanese Journal of Clinical Oncology 200939 837-846. (doi:10.1093/jjco/hyp093)

34 Gatta-Cherifi B, Chabre O, Murat A, Niccoli P, Cardot-Bauters C, Rohmer V, Young J, Delemer B, Boullay HD, Verger MF et al. Adrenal involvement in MEN1. Analysis of 715 cases from the Groupe d'etude des Tumeurs Endocrines database. European Journal of Endocrinology/European Federation of Endocrine Societies 2012166 269-279. (doi:10.1530/EJE-11-0679)

35 Agarwal SK. Multiple endocrine neoplasia type 1. Frontiers of Hormone Research 201341 1-15. (doi:10.1159/000345666)

36 Harding B, Lemos MC, Reed AA, Walls GV, Jeyabalan J, Bowl MR, Tateossian H, Sullivan N, Hough T, Fraser WD et al. Multiple endocrine neoplasia type 1 knockout mice develop parathyroid, pancreatic, pituitary and adrenal tumours with hypercalcaemia, hypophosphataemia and hypercorticosteronaemia. Endocrine-Related Cancer 200916 1313-1327. (doi:10.1677/ERC-09-0082)

37 Shuch B, Ricketts CJ, Vocke CD, Valera VA, Chen CC, Gautam R, Gupta GN, Gomez Macias GS, Merino MJ, Bratslavsky G et al. Adrenal nodular hyperplasia in hereditary leiomyomatosis and renal cell cancer. Journal of Urology 2013189 430-435. (doi:10.1016/j.juro.2012.07.139)

38 Matyakhina L, Freedman RJ, Bourdeau I, Wei M-H, Stergiopoulos SG, Chidakel A, Walther M, Abu-Asab M, Tsokos M, Keil M et al. Hereditary leiomyomatosis associated with bilateral, massive, macronodular adrenocortical disease and atypical cushing syndrome: a clinical and molecular genetic investigation. Journal of Clinical Endocrinology and Metabolism 200590 3773-3779. (doi:10.1210/jc.2004-2377)

39 Espiard S, Drougat L, Libé R, Assié G, Perlemoine K, Guignat L, Barrande G, Brucker-Davis F, Doullay F, Lopez S et al. ARMC5 mutations in a large cohort of primary macronodular adrenal hyperplasia: clinical and functional consequences. Journal of Clinical Endocrinology and Metabolism 2015100 E926-E935. (doi:10.1210/jc.2014-4204)

40 Alencar GA, Lerario AM, Nishi MY, Mariani BM, Almeida MQ, Tremblay J, Hamet P, Bourdeau I, Zerbini MCN, Pereira MA et al. ARMC5 mutations are a frequent cause of primary macronodular adrenal Hyperplasia. Journal of Clinical Endocrinology and Metabolism 201499 E1501-E1509. (doi:10.1210/jc.2013-4237)

41 Zilbermint M, Xekouki P, Faucz FR, Berthon A, Gkourogianni A, Helene Schernthaner-Reiter M, Batsis M, Sinaii N, Quezao MM, Merino $\mathrm{M}$ et al. Primary aldosteronism and ARMC5 variants. Journal of Clinical Endocrinology and Metabolism 2015100 E900-E909. (doi:10.1210/jc.2014-4167)

42 Gagliardi L, Schreiber AW, Hahn CN, Feng J, Cranston T, Boon H, Hotu C, Oftedal BE, Cutfield R, Adelson DL et al. ARMC5 Mutations are common in familial bilateral macronodular adrenal hyperplasia. Journal of Clinical Endocrinology and Metabolism 201499 E1784-E1792. (doi:10.1210/jc.2014-1265)

43 Elbelt U, Trovato A, Kloth M, Gentz E, Finke R, Spranger J, Galas D, Weber S, Wolf C, König K et al. Molecular and clinical evidence for an ARMC5 tumor syndrome: concurrent inactivating germline and somatic mutations are associated with both primary macronodular adrenal hyperplasia and meningioma. Journal of Clinical Endocrinology and Metabolism 2014100 E119-E128. (doi:10.1210/jc.2014-2648)

44 Cao Y, He M, Gao Z, Peng Y, Li Y, Li L, Zhou W, Li X, Zhong X, Lei Y etal. Activating hotspot L205R mutation in PRKACA and adrenal Cushing's syndrome. Science 2014344 913-917. (doi:10.1126/science.1249480)

45 Zhu J, Cui L, Wang W, Hang X-Y, Xu A-X, Yang S-X, Dou J-T, Mu Y-M, Zhang $X \&$ Gao J-P. Whole exome sequencing identifies mutation of EDNRA involved in ACTH-independent macronodular adrenal hyperplasia. Familial Cancer 201312 657-667. (doi:10.1007/ s10689-013-9642-y)

Received 1 June 2015

Revised version received 4 August 2015

Accepted 10 August 2015 